\title{
Simulation as an Educational Tool in the Pediatric Cardiac Intensive Care Unit
}

\author{
Tarif A. Choudhury ${ }^{1}$ (D) Jonathan N. Flyer ${ }^{2} \cdot$ Mary E. McBride $^{3}$ \\ Accepted: 14 April 2021 / Published online: 25 May 2021 \\ (C) The Author(s), under exclusive licence to Springer Science+Business Media, LLC, part of Springer Nature 2021
}

\begin{abstract}
Purpose of Review This review highlights the use of simulation as an educational tool in the highly specialized pediatric cardiac intensive care unit (PCICU).

Recent Findings Healthcare simulation is used in high acuity medical environments to test healthcare systems. Healthcare simulation can improve team training, patient safety, and improve medical decision-making. Complex physiologies in the PCICU demand effective teamwork to consistently deliver high-quality patient care. Simulation-based PCICU learning objectives depend on a structured cognitive load framework to account for individual learner abilities, team constructs, and healthcare resources.

Summary PCICU simulation programs are strengthened by utilizing traditional education theory, with careful consideration of complex physiologies, interprofessional personnel, and center-specific resources. Virtual platforms should continue to evolve to provide additional, more convenient venues for individual learners and teams. Healthcare systems should frequently intersect with simulation educators to create relevant learning objectives that will contribute to patient safety, improve team performance, and patient outcomes.
\end{abstract}

Keywords Healthcare simulation $\cdot$ Pediatric cardiac intensive care $\cdot$ Pediatric cardiology $\cdot$ Medical education $\cdot$ Quality and patient safety $\cdot$ Crisis resource management

\section{Introduction}

This review will highlight the use of simulation as an educational tool in the pediatric cardiac intensive care unit (PCICU). It will briefly describe key features of the highly specialized

This article is part of the Topical Collection on Intensive Care Medicine

Tarif A. Choudhury

tc2697@cumc.columbia.edu

1 Department of Pediatrics, Divisions of Pediatric Critical Care Medicine and Pediatric Cardiology, Columbia University Medical Center, Morgan Stanley Children's Hospital of New York, 3959 Broadway Avenue, New York, NY 10032, USA

2 Department of Pediatrics, Division of Pediatric Cardiology, The Robert Larner, M.D. College of Medicine at The University of Vermont, University of Vermont Children's Hospital, Burlington, VT, USA

3 Departments of Pediatrics and Medical Education, Divisions of Cardiology and Critical Care Medicine, Ann \& Robert H Lurie Children's Hospital of Chicago, Northwestern University Feinberg School of Medicine, Chicago, IL, USA
PCICU care environment to consider when creating simulation-based learning objectives. It will review and apply educational theory to create PCICU simulation curricula. Emphasis will be placed on identifying examples in the literature regarding the use of simulation in the PCICU. In addition, we will review the principles of crisis resource management and describe its use in PCICU team-based simulation. Finally, we will describe the use of simulation as it pertains to PCICU-related system testing.

\section{History and Drivers of Healthcare Simulation}

Healthcare simulation is any device or set of conditions that attempts to represent the patient authentically [1]. The simulation field derives from the tenth century acupuncture practice when real time feedback was provided for anatomic placement of healing instruments $[2,3]$. Until the twentieth century, healthcare simulation was limited to simple task trainers to demonstrate skill acquisition, particularly in the fields of obstetrics, general surgery, and ophthalmology [4]. In the modern era, "Resusci Anne" was the first manikin to gain 
commercial success, offering much broader healthcare delivery and instruction of cardiopulmonary resuscitation [5].

Healthcare simulation evolved to include integrated simulators [6], which combine a manikin with computer controls resulting in anatomic and physiologic fidelity to represent clinical status. The original integrated simulator, "SimOne," emerged in the early 1960s and could be manipulated to represent different cardiac and respiratory pathologies [7]. Despite promising early reports of being an effective training tool, the exorbitant cost of "SimOne" and the dominating apprenticeship-based training model in healthcare resulted in the failure to achieve widespread acceptance of simulationbased training $[8,9]$.

Drivers of modern healthcare simulation have included societal expectation, political accountability, and opportunity for professional regulation. The old adage, "see one, do one, teach one," refers to an apprenticeship model and real patient encounters to progress learners toward independence and proficiency [10]. The landmark report, "To err is human" revealed 98,000 medical mistakes occurred due to human error [11] and further supported the need for healthcare organizations to "see one, simulate many, do one then teach one." [12]

\section{Distinguishing Features of the PCICU}

\section{Physiology}

The complex physiologies housed in the PCICU demand tailored approaches to acute events [13]. Children with congenital heart disease (CHD) frequently have limited physiologic reserve, often a result of an abnormal relationship of oxygen delivery to consumption. The medical team is charged with identifying atypical causes for typical chief complaints. A common example is the approach to the hypoxemic infant with a systemic to pulmonary artery shunt. This scenario calls for a strategic approach to recognize shunt obstruction as opposed to more typical causes of pediatric hypoxemia such as pneumonia or primary ventilation derangements. This example highlights how limited exposure to complex cardiac physiologies makes simulation an excellent educational tool to approach and rehearse high-stakes, low frequency scenarios. Figure 1 outlines key physiologic, personnel, resource-related, and environmental factors to consider when creating learning objectives for PCICU simulation programs.

\section{Personnel and Places}

The complicated physiology and limited reserve of children with CHD admitted to the PCICU necessitate care by specialized teams. As a result, simulation sessions focused on team training are vital to effectively care for this population. There is heterogeneity in PCICU team leadership and training backgrounds, which may result in practice variation $[14,15 \cdot]$. Differences in the makeup of PCICU teams also extend to the front-line. Depending on the graduate medical education institutional footprint, front-line providers may range from advanced practice providers to residents and/or fellows [16]. Each staffing model has a distinct background and perspective resulting in differences in continuity of care and baseline knowledge.

PCICU teams also need to be prepared for emergencies beyond the confines of the unit. Acute events in the interventional radiology suite, emergency room, and cardiac catheterization lab add an extra layer of challenge to this population [17]. Simulation can mitigate the heightened anxiety that accompanies the demands of juggling complex physiology outside the familiar PCICU environment [18].

\section{Procedures}

Institutional resource limitations should prompt different clinical responses by PCICU teams. Variations in infrastructure should shape institutional clinical pathways. PCICU teams without robust cardiac catheterization labs may focus simulation-based training on early recognition of residual anatomic lesions followed by safe inter-hospital transport. Simulation-based educational objectives may concentrate on the practice of stabilization and safe transfer relative to the center's ability to provide mechanical circulatory support or facilitate heart transplant. Smaller cardiac centers are encouraged to recognize when heart failure treatment has exhausted medical therapy, and transfer patients to centers with a transplant program. Larger centers with greater resources can provide more specialized diagnostic and therapeutic modalities including catheter-based and surgical interventions. Emergent re-sternotomy and balloon atrial septostomy are among the unique bedside procedures a PCICU team needs to be equipped to handle. Patient conditions refractory to medical therapy with precipitous deterioration may call for a wellchoreographed team response to initiate extracorporeal membrane oxygenation (ECMO). Such centers may focus their educational initiatives on task trainers to facilitate surgical proficiency and vascular cannulation for ECMO. Alternative forms of mechanical circulatory support include ventricular assist devices, which require a team to be familiar with troubleshooting acute clinical events. These complex, high-stakes, low frequency events make simulation an excellent educational tool to prepare teams to care for children undergoing these procedures.

\section{Educational Theory and SimZones in the PCICU}

Safe and effective real-time pediatric cardiac critical care practice requires mastery of abnormal anatomy and physiology, 
Fig. 1 Distinguishing features of PCICU

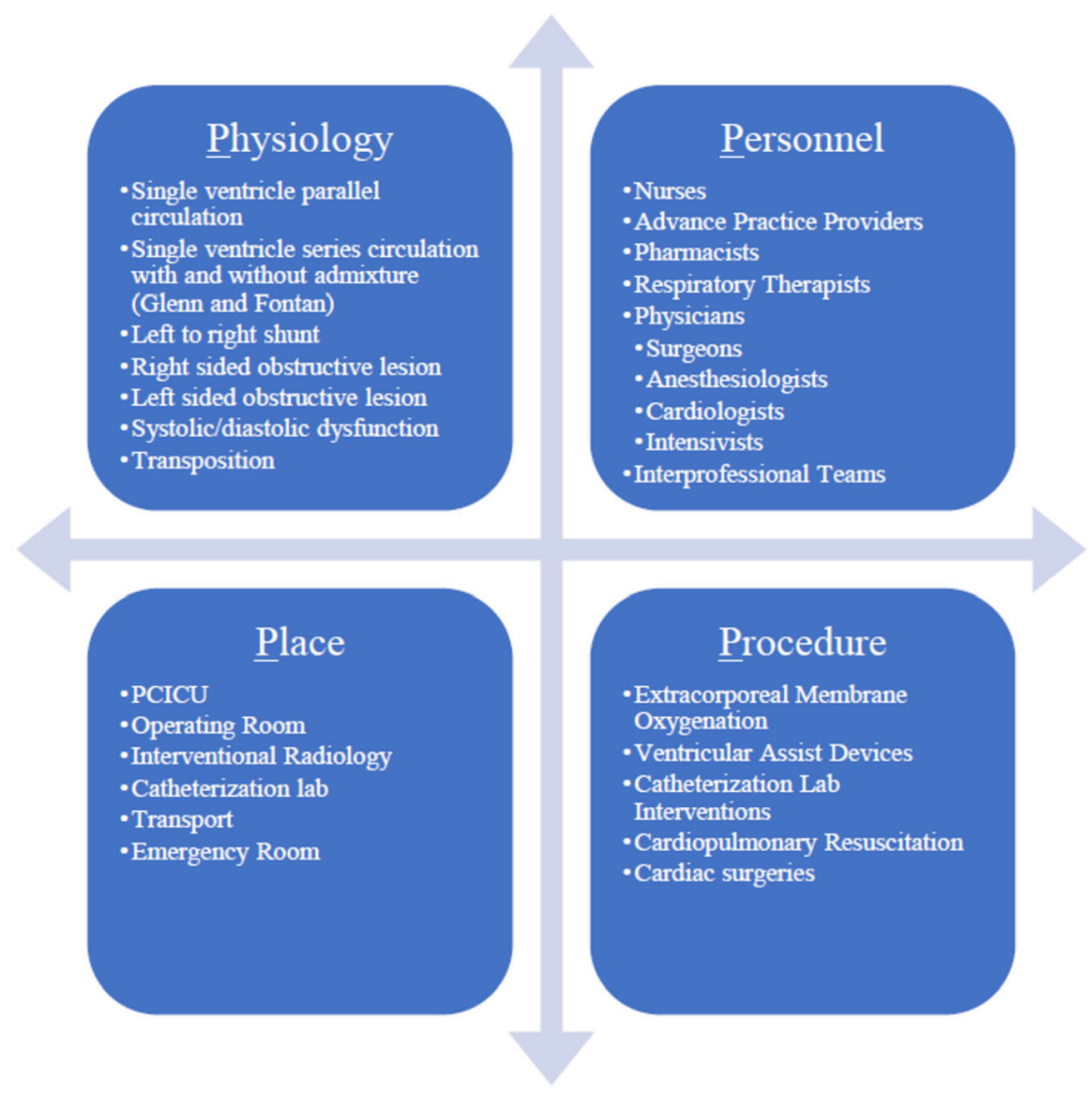

advanced procedural skills, and team communication [19••]. Simulation education can address a spectrum of skills related to critical care and systematically help learners gain expertise in a high-stake clinical environment. Like any other educational curriculum, one using simulation in the PCICU may draw from frameworks such as Bloom's taxonomy. Educational theories including Kolb's experiential learning and Sweller's cognitive load theory can help direct individual and team-based learning goals and objectives.

Bloom's taxonomy is an educational assessment framework to evaluate learner knowledge, skill acquisition, and application [20]. The original 1956 taxonomy classifies cognitive domains into lower order (knowledge, comprehension, application) and higher order (analysis, synthesis, evaluation) skills. Lower order domains measure basic fact retention (knowledge) and the ability to identify the information in context (comprehension), building up to utilizing it in a process (application). Stepwise PCICU examples (Fig. 2) may be learning the definition of hypoxemia (knowledge), then comparing the presentations of different causes of hypoxemia in CHD (comprehension), then generating a likely diagnosis for hypoxemia in the newborn with critical CHD based on presentation, laboratory, and imaging data (application). Higher order domains move the learner into critical thinking (analysis), next steps of decision and planning (synthesis), and finally learner reflection (evaluation). Stepwise higher order
PCICU examples may include differentiating between evidence and expert opinion-based management strategies for hypoxemia following cavopulmonary anastomosis (analysis), formulating a complete cardiac care plan for post-operative hypoxemia (synthesis), and critically appraising the Stage II post-operative clinical course including evidence-based literature and how it may change one's practice (evaluation). Instructors should clearly identify goals for each training level and modify based on learner ability [20]. The 2001 revised taxonomy further identifies four types of knowledge (factual, conceptual, procedural, metacognitive), with more emphasis on a continuum of cognitive processes and greater applicability to modern training [21]. Utilizing a similar framework, PCICU simulation can provide training in affective (communication) and psychomotor (procedures/tasks) domains.

Experiential learning, as described by Kolb, relies on prior experience to drive future learning states [22]. The learning cycle is continuous, and incorporates four phases: concrete experience, reflective observation, abstract conceptualization, and active experimentation (Fig. 3). Medical professionals offer varying levels of clinical backgrounds (concrete experience) based on training, and new PCICU experiences can be offered through simulation. These experiences can be analyzed and reflected upon through simulation scenario debriefing (reflective observation), allowing learners to 




Fig. 2 PCICU simulation-based learning objectives using Bloom's taxonomy

analyze new concepts (abstract conceptualization) and then practice application of these new concepts (active experimentation). Repeated simulation directly assists with objective performance evaluation and provides structured and supportive opportunities to master new care strategies.

Cognitive load theory outlines processes through which long-term memory develops from new active learning [23] and is readily applicable to simulation education design [24•]. Cases can be matched to individual learner ability, both across and within all three types of cognitive loads: intrinsic (complexity of a learning task), extrinsic (the environmental stressors), and germane (organizational efforts to process information). PCICU simulation is well suited to expand learning objectives with only small changes in case details. This framework allows the educator to gradually increase cognitive load based on learner ability, and gently relax it if the learner is not ready, thereby still preparing the learner for critical thinking and acute care.

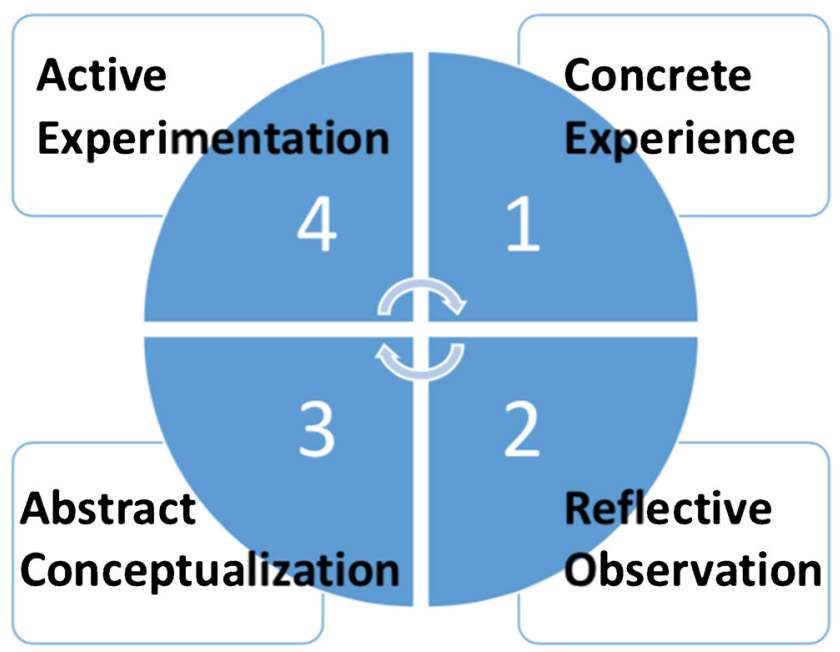

Fig. 3 Experiential learning cycle
The SimZones framework, developed by the Boston Children's Hospital simulation program, incorporates these theories, and is an example of a graduated critical care case design format [25••]. It covers the spectrum of simulation learning, spanning from individual auto feedback (Zone 0), to foundational instruction (Zone 1), acute situational instruction (Zone 2), team and system development (Zone 3), and real-life debriefing and development (Zone 4). The program provides a structured cognitive load framework to learn across taxonomies and build reflective experience.

Examples of PCICU educational curricula are outlined in Table 1, which span from Zone 0 to Zone 4 . Zone 0 is illustrated using task trainers to achieve competency in extracorporeal membrane oxygenation (ECMO) cannulation [26]. Examples of Zone 1 include the use of task trainers for echocardiography and intra-operative surgical skills [27•, [28•]]. Simulation to achieve specific situational competency (Zone 2 ) is intended to prepare learners from individual disciplines and/or educational levels (i.e., cardiologists, intensivists, anesthesiologists, nurses, and nurse practitioners) to respond to different acute events [29-32•]. Team training (Zone 3) has included acute events related to physiologic derangements and need for mechanical circulatory support [33-35]. Video recording of live cardiac arrests (Zone 4) has encouraged more objective review of acute events by an interprofessional team, allowing for a more thoughtful debrief [36].

\section{Crisis Resource Management in the PCICU}

\section{History of Crisis Resource Management}

Crisis resource management (CRM) refers to the principles utilized to optimize non-technical skills required for effective teamwork in an acute event [37]. Five major components of CRM are frequently stressed including role clarity, communication, personnel support, resource use, and global 
Table 1 PCICU curricula references by SimZones

\begin{tabular}{|c|c|c|c|c|}
\hline SimZone & Type of Training & Type of Learners & Title & Authors/Journal \\
\hline 0 & $\begin{array}{l}\text { ECMO cannulation } \\
\text { skills trainer }\end{array}$ & CT Surgeons/fellows & $\begin{array}{l}\text { An extracorporeal membrane oxygenation } \\
\text { cannulation curriculum featuring a novel } \\
\text { integrated skill trainer leads to improved } \\
\text { performance among pediatric cardiac } \\
\text { surgery trainees }\end{array}$ & Allan et al Simulation in Healthcare 2013 \\
\hline 1 & $\begin{array}{l}\text { Echocardiography } \\
\text { skills trainer }\end{array}$ & $\begin{array}{l}\text { Pediatric cardiology } \\
\text { fellows }\end{array}$ & $\begin{array}{l}\text { Effectiveness of echocardiography simulation } \\
\text { training for pediatric cardiology fellows in } \\
\text { CHD }\end{array}$ & Dayton et al Cardiology in the Young 2018 \\
\hline 1 & Surgical skills trainer & CT Surgeons/fellows & $\begin{array}{l}\text { Hands-on surgical simulation in congenital } \\
\text { heart surgery: literature review and future } \\
\text { perspective }\end{array}$ & $\begin{array}{l}\text { Hussein N. et al. Hands-On Semin Thorac } \\
\text { Cardiovasc Surg. } 2020\end{array}$ \\
\hline 2 & Medical management & Pediatric residents & $\begin{array}{l}\text { Pediatric heart disease simulation curriculum: } \\
\text { educating the pediatrician }\end{array}$ & Harris et al Pediatric Cardiology 2017 \\
\hline 2 & Medical management & Nurses/APNs & $\begin{array}{l}\text { Effectiveness of a simulation-based } \\
\text { educational program in a pediatric cardiac } \\
\text { intensive care unit }\end{array}$ & Kane et al Journal of Pediatric Nursing 2010 \\
\hline 2 & Medical management & $\begin{array}{l}\text { Cardiology, PICU } \\
\text { fellows, APNs, } \\
\text { nurses }\end{array}$ & $\begin{array}{l}\text { "Just-In-Time" simulation training using 3-D } \\
\text { printed cardiac models after congenital } \\
\text { cardiac surgery }\end{array}$ & $\begin{array}{l}\text { Olivieri et al. World Journal for Pediatric and } \\
\text { Congenital Heart Surgery } 2016\end{array}$ \\
\hline 2 & Medical management & Nurse practitioners & $\begin{array}{l}\text { A multi-institutional simulation boot camp for } \\
\text { pediatric cardiac critical care nurse } \\
\text { practitioners }\end{array}$ & $\begin{array}{l}\text { Brown Ket al. Pediatric Critical Care Medicine } \\
\quad 2018\end{array}$ \\
\hline 3 & $\begin{array}{l}\text { Medical management } \\
\text { and team training }\end{array}$ & $\begin{array}{l}\text { Interprofessional } \\
\text { PCICU team }\end{array}$ & $\begin{array}{l}\text { Pediatric ventricular assist device simulation: } \\
\text { constructing an in-situ simulation training }\end{array}$ & $\begin{array}{l}\text { Villa et al Progress in Pediatric Cardiology } \\
\quad 2017\end{array}$ \\
\hline
\end{tabular}

program to facilitate education and competency

2/3 Medical management and team training

Medical management and team training

Medical management and team training and team training

Medical management and team training

Medical management and team training

Medical management and team training

Medical management and team training

Interprofessional and team training and team training
Interprofessional PCICU team PCICU team fellows, APNs, nurses

PICU fellows, pediatric residents, nurses

Interprofessional PCICU team

Interprofessional PCICU team

Interprofessional PCICU team

Interprofessional PCICU team

MDs, NPs, nurses

Interprofessional PCICU team
Cardiology, PICU
Acute hypoxemia in infants with cyanotic complex cardiac anatomy: simulation cases for pediatric fellows

Critical cardiopulmonary event series: four simulations for pediatric ICU fellows, critical care nurses, and pediatric residents

Improving teamwork, confidence, and collaboration among members of a pediatric cardiovascular intensive care unit multidisciplinary team using simulation-based team training

Multidisciplinary simulation-based team training: knowledge acquisition and shifting perception

Simulation training improves team dynamics and performance in a low-resource cardiac intensive care unit

Simulation-based training delivered directly to Allan et al J Thorac Cardiovasc Surg. 2010 the pediatric cardiac intensive care unit engenders preparedness, comfort, and decreased anxiety among multidisciplinary resuscitation teams

Impacts of a pediatric extracorporeal cardiopulmonary resuscitation (e-CPR) simulation training program

Implementation of an extracorporeal cardiopulmonary resuscitation simulation program reduces extracorporeal cardiopulmonary resuscitation times in real patients

Applying educational theory to interdisciplinary education in pediatric cardiac critical care

Cardiac resuscitation events: one eyewitness is not enough
Peddy S. MedEd Portal 2018

Bergman et a MedEd Portal 2020

Figueroa et al Pediatric Cardiology 2012

Cory et al Clinical Simulation in Nursing 2020

Emani et al Annals of Pediatric Cardiology 2018

Sawyer et al Acad Pediatr. 2019

Su L et al Pediatr Crit Care Med. 2014

McBride et al World Journal for Pediatric and Congenital Heart Surgery 2019

Su et al Pediatric Critical Care Medicine 2015 
assessment. CRM naturally has a place in the high acuity, interprofessional healthcare environment and followed the airline industry's application of crew resource management [38]. Crew resource management principles were an initiative prompted by several airline disasters related to ineffective teamwork and communication [39]. Medical errors that result from ineffective teamwork during patient care draw parallel to in-flight errors due to improper airline crew resource management. Anesthesia was among the first medical subspecialties to adopt CRM training principles [40] and apply it through simulation-based team training (SBTT). The objective of this training was to improve team functioning with a focus on communication to mitigate the risk of patient harm.

\section{PCICU CRM Examples}

One benefit of SBTT is the ability to flatten the hierarchy between team members. Among the reported challenges of airline teams that contributed to crew safety was the reluctance of team members to speak freely to authority. The attitudes of teams in the pediatric cardiac operating room revealed perceived authority gradients as barriers to safely voice concerns to mitigate the risk of errors [41]. Allan et al. revealed in-situ SBTT in the PCICU increased the likelihood of team members voicing concerns to the team leader when there was perceived error in medical management [42]. The ability and willingness to speak up and challenge authority gradients is an integral part of decreasing patient harm. Simulation can be a psychologically safe container, allowing for rehearsal of an emergency in the PCICU where learners are challenged and held to high standards but not humiliated or intimidated [43]. This focuses the learner's reflection on actions and feedback. Implementation of SBTT can also be used to unmask lapses in understanding CRM principles. PCICU in-situ SBTT has been used to identify inaccuracies in defining closed-loop communication, illustrate key principles of effective teamwork, and define fixation errors [44].

Team dynamics are tested in acute events and SBTT can improve self-reporting of team performance. SBTT in the PCICU was utilized to apply new open chest algorithms with improvements in important team dynamics parameters including confidence when performing in an acute event, mutual respect among team members, team member empowerment, and improved closed-loop communication among team members [45]. SBTT has been used to improve PCICU provider perceptions of preparedness, comfort, and anxiety in resourcelimited settings, speaking to the translatability of SBTT across care models. Emani et al demonstrated the feasibility and efficacy of SBTT in a resource limited PCICU by utilizing video review to longitudinally track improvements in role clarity and communication [46•].

\section{Testing Healthcare Systems in the PCICU}

Simulation-based clinical systems testing (SBCST) allows for realization of interactions between people and the environment [47] . SBCST allows insights into process implementation and to identify latent safety threats (LST) before errors occur as a result of human factors or hospital design. LST are defined as "systems-based threats to patient safety that can materialize at any time and are previously unrecognized by health care providers, unit directors or hospital administration and pose risk to the patient and/or healthcare team" [48]. A proposed framework to recognize LST includes categorizing them into medication, equipment, and resources/system issues [49].

Although the PCICU is particularly vulnerable to LST, SBCST has not yet been widely adopted. Adler et al. used in-situ simulation to identify LST when moving the physical location of a children's hospital [50]. Simulations included surgical cases in the cardiac OR, acute events in the cardiac catheterization lab, and emergencies in the PCICU. As a result, issues were unmasked regarding equipment code alarms, patient care concerns, and hospital signage. With the advent of new technologies, surgeries, and teams charged with leading these initiatives, SBCST may prospectively reveal how personnel interact with new environments and therapies.

\section{Future Direction}

The future of the PCICU includes dynamic care models and innovative therapies that will require teams to remain current and ready to address medical emergencies. Cardiac care teams will need continuous preparation for acute events in and outside the PCICU. The resultant limitations the COVID-19 pandemic placed on interprofessional staff from attending live simulation events, revealed the need for effective distancebased simulation. Educational tools such as game play, virtual reality, and telesimulation should be an important focus of future PCICU simulation-based training initiatives. Larger PCICU programs may focus on using virtual platforms to share clinical pearls with smaller centers. PCICU morbidity and mortality conferences should be used as a needs assessment to generate educational and team learning objectives for simulation programs. Future research should evolve beyond self-reporting learner outcomes and translate to improvement in measurable clinical outcomes.

\section{Conclusion}

The highly complex PCICU warrants consideration of challenging physiology, team composition, and resource availability when creating simulation-based learning objectives. 
Healthcare simulation has evolved beyond simply addressing the needs of individual learners. Limitations of individual learners, teams, and center-specific resources should impact cognitive loading of simulation scenarios. Simulation should be utilized as a psychologically safe educational tool with a goal of building team communication skills and optimizing patient safety.

\section{References}

Papers of particular interest, published recently, have been highlighted as:

- Of importance

•- Of major importance

1. Issenberg SB, Scalese RJ. Simulation in health care education. Perspect Biol Med. 2008 Winter;51(1):31-46.

2. Maciocia G. History of acupuncture. J Chin Med 1982; 9:9Y15.

3. Available at: $\mathrm{http}: / /$ en.tcm-china.info/acupuncture/origin/ 75565 _1. shtml. Accessed May 26, 2011.

4. Owen H. Early use of simulation in medical education. Simul Healthc. 2012 Apr;7(2):102-16.

5. Tjomsland N, Baskett P, Asmund S. Lærdal. Resuscitation. 2002;53(2):11519.

6. Bradley P. The history of simulation in medical education and possible future directions. Med Educ. 2006 Mar;40(3):254-62.

7. Denson JS, Abrahamson S. A computer-controlled patient simulator. JAMA. 1969;208(3):504-8.

8. Chiniara G, Crelinsten L. Chapter 1 - A brief history of clinic simulation: how did we get here? Clinical simulation (second edition). Academic Press. 2019, Pages 3-16.

9. Owen H. Simulation in healthcare education: an extensive history. New York: Springer; 2016. p. 456.

10. Rohrich RJ. "See one, do one, teach one": an old adage with a new twist. Plast Reconstr Surg. 2006;118:257-8.

11. Kohn LT, Corrigan JM, Donaldson MS. To err is human - building a safer health system. Washington: National Academy Press; 1999.

12. Yanagawa B, Ribeiro R, Naqib F, Fann J, Verma S, Puskas JD. See one, simulate many, do one, teach one: cardiac surgical simulation. Curr Opin Cardiol. 2019 Sep;34(5):571-7.

13. Marino BS, Tabbutt S, MacLaren G, Hazinski MF, et al. American Heart Association Congenital Cardiac Defects Committee of the Council on Cardiovascular Disease in the Young; Council on Clinical Cardiology; Council on Cardiovascular and Stroke Nursing; Council on Cardiovascular Surgery and Anesthesia; and Emergency Cardiovascular Care Committee. Cardiopulmonary resuscitation in infants and children with cardiac disease: a scientific statement from the American Heart Association. Circulation. 2018 May 29;137(22): e691-e782.

14. Burstein DS, Rossi AF, Jacobs JP, Checchia PA, Wernovsky G, Li JS, et al. Variation in models of care delivery for children undergoing congenital heart surgery in the United States. World J Pediatr Congenit Heart Surg. 2010 Apr;1(1):8-14.

15. ME MB, Beke DM, Fortenberry JD, Imprescia A, et al. Education and training in pediatric cardiac critical care. World Journal for Pediatric and Congenital Heart Surgery. 2017;8(6):707-14 Remarks on the importance of simulation as an educational tool in the PCICU.
16. Horak RV, Alexander PM, Amirnovin R, Klein MJ, Bronicki RA, Markovitz BP, et al. Pediatric cardiac intensive care distribution, service delivery, and staffing in the United States in 2018. Pediatr Crit Care Med. 2020 Sep;21(9):797-803.

17. Odegard KC, Bergersen L, Thiagarajan R, Clark L, Shukla A, Wypij D, et al. The frequency of cardiac arrests in patients with congenital heart disease undergoing cardiac catheterization. Anesth Analg. 2014 Jan;118(1):175-82.

18. Bong CL, Lightdale JR, Fredette ME, Weinstock P. Effects of simulation versus traditional tutorial-based training on physiologic stress levels among clinicians: a pilot study. Simul Healthc. 2010 Oct;5(5):272-8.

19.• ME MB, Almodovar MC, Florez AR, Imprescia A. Applying educational theory to interdisciplinary education in pediatric cardiac critical care. World J Pediatr Congenit Heart Surg. 2019;10(6): 742-9 Reviews educational and cognitive load theory as it pertains to the creation of learning objectives in the PCICU. This paper also introduces the application of SimZones in the PCICU.

20. Adams NE. Bloom's taxonomy of cognitive learning objectives. J Med Libr Assoc. 2015 Jul;103(3):152-3.

21. Orgill BD, Nolin J. Learning taxonomies in medical simulation. [Updated 2020 Jul 6]. In: StatPearls [Internet]. Treasure Island (FL): StatPearls Publishing; 2020.

22. Kolb DA. Experiential learning: experience as the source of learning and development. Englewood Cliffs, NJ: Prentice Hall. 1984 Jan.

23. van Merriënboer JJ, Sweller J. Cognitive load theory in health professional education: design principles and strategies. Med Educ. 2010;44(1):85-93.

24.• ME MB, Almodovar MC, Florez AR, Imprescia A. Applying educational theory to interdisciplinary education in pediatric cardiac critical care. World J Pediatr Congenit Heart Surg. 2019;10(6): $742-9$ Reviews educational and cognitive load theory as it pertains to the creation of learning objectives in the PCICU. This paper also introduces the application of SimZones in the PCICU.

25.• Roussin CJ, SimZones WP. An organizational innovation for simulation programs and centers. Acad Med. 2017;92(8):1114-20 Introduced SimZones, a framework used to create simulationbased learning objectives utilizing cognitive load theory and type of simulation training.

26. Allan CK, Pigula F, Bacha EA, Emani S, Fynn-Thompson F, Thiagarajan RR, et al. An extracorporeal membrane oxygenation cannulation curriculum featuring a novel integrated skills trainer leads to improved performance among pediatric cardiac surgery trainees. Simul Healthc. 2013 Aug;8(4):221-8.

27. Dayton JD, Groves AM, Glickstein JS, Flynn PA. Effectiveness of echocardiography simulation training for paediatric cardiology fellows in CHD. Cardiol Young. 2018;28(4):611-5 Describes the use of a pediatric echocardiography task trainer to improve the ability of pediatric cardiology fellows to perform and interpret echocardiograms.

28. Hussein N, Honjo O, Haller C, Hickey E, et al. Hands-on surgical simulation in congenital heart surgery: literature review and future perspective. Semin Thorac Cardiovasc Surg Spring. 2020;32(1): 98-105 Reviews examples of task trainers used to train congenital heart surgeons in their technical skills when operating on complex congenital heart surgery.

29. Harris TH, Adler M, Unti SM, McBride ME. Pediatric heart disease simulation curriculum: educating the pediatrician. Congenit Heart Dis. 2017 Jul;12(4):546-53.

30. Kane J, Pye S, Jones A. Effectiveness of a simulation-based educational program in a pediatric cardiac intensive care unit. J Pediatr Nurs. 2011 Aug;26(4):287-94. 
31. Olivieri LJ, Su L, Hynes CF, Krieger A, Alfares FA, Ramakrishnan $\mathrm{K}$, et al. "Just-In-Time" simulation training using 3-D printed cardiac models after congenital cardiac surgery. World J Pediatr Congenit Heart Surg. 2016 Mar;7(2):164-8.

32. Brown KM, Mudd SS, Hunt EA, Perretta JS, et al. A multiinstitutional simulation boot camp for pediatric cardiac critical care nurse practitioners. Pediatr Crit Care Med. 2018;19(6):564-71 Describes the feasibility and impact of utilizing simulationbased training for PCICU nurse practitioners.

33. Villa CR, Schubert A, Gardner A, Fields K, Burkhart L, Morales DLS, et al. Pediatric ventricular assist device simulation: constructing an in-situ simulation training program to facilitate education and competency. Prog Pediatr Cardiol. 2017;47:34-6.

34. Peddy SB. Acute hypoxemia in infants with cyanotic complex cardiac anatomy: simulation cases for pediatric fellows. MedEdPORTAL. 2018;17.

35. Bergman CM, Howell J. Critical cardiopulmonary event series: four simulations for Pediatric ICU fellows, critical care nurses, and pediatric residents. MedEdPORTAL. 2020;20.

36. Su L, Waller M, Kaplan S, Watson A, Jones M, Wessel DL. Cardiac resuscitation events: one eyewitness is not enough. Pediatr Crit Care Med. 2015 May;16(4):335-42.

37. Flin R, Maran N. Identifying and training non-technical skills for teams in acute medicine. Qual Saf Health Care. 2004 Oct;13(Suppl 1):i80-4.

38. Lauber JK. Cockpit resource management: background and overview, cockpit resource management training. In: Orlady HW, Foushee HC, eds. Cockpit resource management training: Proceedings of the NASA/MAC Workshop. Moffett Field, CA: NASA-Ames Research Center, 1987; CP-2455.

39. Jensen RS, Biegelski CS. Cockpit resource management. In: Jensen RS, editor. Aviation Psychology. Aldershot, England: Gower Technology; 1989. p. 176-209.

40. Howard SK, Gaba DM, Fish KJ, Yang G, et al. Anesthesia crisis resource management training: teaching anesthesiologists to handle critical incidents. Aviat Space Environ Med. 63:763-70.

41. Bognár A, Barach P, Johnson JK, Duncan RC, Birnbach D, Woods D, et al. Errors and the burden of errors: attitudes, perceptions, and the culture of safety in pediatric cardiac surgical teams. Ann Thorac Surg. 2008;85(4):1374-81.
42. Allan CK, Thiagarajan RR, Beke D, Imprescia A, Kappus LJ, Garden A, et al. Simulation-based training delivered directly to the pediatric cardiac intensive care unit engenders preparedness, comfort, and decreased anxiety among multidisciplinary resuscitation teams. J Thorac Cardiovasc Surg. 2010;140(3):646-52.

43. Rudolph JW, Raemer DB, Simon R. Establishing a safe container for learning in simulation: the role of the presimulation briefing. Simul Healthc. 2014;9(6):339-49.

44. Cory MJ, Hebbar KB, Colman N, Pierson A, Clarke SA. Multidisciplinary simulation-based team training: knowledge acquisition and shifting perception. Clinical Simulation in Nursing. 2020;41(C):14-21.

45. Figueroa MI, Sepanski R, Goldberg SP, Shah S. Improving teamwork, confidence, and collaboration among members of a pediatric cardiovascular intensive care unit multidisciplinary team using simulation-based team training. Pediatr Cardiol. 2013;34(3):612-9.

46. Emani SS, Allan CK, Forster T, Fisk AC, et al. Simulation training improves team dynamics and performance in a low-resource cardiac intensive care unit. Ann Pediatr Cardiol. 2018;11(2):130-6 Describes the use of simulation-based training to improve knowledge of crisis resource management principles.

47. Colman N, Doughty C, Arnold J, Stone K, et al. Simulation-based clinical systems testing for healthcare spaces: from intake through implementation. Adv Simul (Lond). 2019; 4. Describes the use of simulation as a platform to reveal latent safety threats in the pediatric intensive care unit.

48. Alfredsdottir H, Bjornsdottir K. Nursing and patient safety in the operating room. J Adv Nurs. 2008 Jan;61(1):29-37.

49. Patterson MD, Geis GL, Falcone RA, LeMaster T, Wears RL. In situ simulation: detection of safety threats and teamwork training in a high-risk emergency department. BMJ Qual Saf. 2013 Jun;22(6): 468-77.

50. Adler MD, Mobley BL, Eppich WJ, Lappe M, Green M, Mangold $\mathrm{K}$. Use of simulation to test systems and prepare staff for a new hospital transition. J Patient Saf. 2018 Sep;14(3):143-7.

Publisher's Note Springer Nature remains neutral with regard to jurisdictional claims in published maps and institutional affiliations. 